\title{
Numerical Simulations of V-Shaped Plates Subjected to Blast Loadings: A Validation Study
}

\author{
Mohd Zaid Othman ${ }^{1}$, Qasim H. Shah ${ }^{2}$, Muhammad Akram Muhammad Khan ${ }^{1}$, Tan Kean Sheng ${ }^{1}$, M. A. Yahaya ${ }^{3}$, \\ Amir Radzi Ab Ghani ${ }^{3}$, Md Fuad Shah Koslan ${ }^{4}$, Jestin J. ${ }^{1}$ \& Ahmad Mujahid Ahmad Zaidi ${ }^{1}$ \\ ${ }^{1}$ Department of Mechanical Engineering, National Defence University of Malaysia, Kuala Lumpur, Malaysia \\ ${ }^{2}$ Deparment of Mechanical Engineering, Faculty of Engineering, International Islamic University of Malaysia, \\ Malaysia \\ ${ }^{3}$ Faculty of Mechanical Engineering, Universiti Teknologi MARA, Shah Alam, Malaysia \\ ${ }^{4}$ Royal Malaysian Air Force, Ministry of Defence, Kuala Lumpur, Malaysia \\ Correspondence: Mohd Zaid Othman, Department of Mechanical Engineering, Faculty of Engineering, National \\ Defence University of Malaysia, Kuala Lumpur, Malaysia. Tel: 6012-404-5002. E-mail: zaid002@gmail.com
}

Received: May 19, 2016

doi:10.5539/mas.v10n11p203
Accepted: June 8, 2016

Online Published: August 18, 2016

URL: http://dx.doi.org/10.5539/mas.v10n11p203

\begin{abstract}
A series of numerical simulations utilizing LS-DYNA was performed to determine the mid-point deformations of V-shaped plates due to blast loading. The numerical simulation results were then compared with experimental results from published literature. The V-shaped plate is made of DOMEX 700 and is used underneath an armour personal carrier vehicle as an anti-tank mine to mitigate the effects of explosion from landmines in a battlefield. The performed numerical simulations of blast loading of $\mathrm{V}$-shaped plates consisted of various angles i.e. $60^{\circ}, 90^{\circ}$, $120^{\circ}, 150^{\circ}$ and $180^{\circ}$; variable mass of explosives located at the central mid-point of the V-shaped vertex with various stand-off distances. It could be seen that the numerical simulations produced good agreement with the experimental results where the average difference was about $26.6 \%$.
\end{abstract}

Keywords: blast loading, numerical simulation, V-shaped plates, DOMEX 700, LS-DYNA

\section{Introduction}

Armour personal carriers (APC) were designed for protection against small arms bullets and shrapnel from hand grenades. The emergence of terrorist groups have brought in a new threat in the form of improvised explosive devices (IED) which are planted by the roadside or buried on dirt roads to obstruct the movement of law enforcement agencies. This put forward a demand for redesign of APC as well as some add-on gadgets for the already operational fleet of vehicles. An IED or landmine generate high speed fragments and a blast wave. The type of damage inflicted by the two is different and fall into different category of physical phenomena. The armour plate used to build vehicles is already good enough for protection against fragments, however, the blast wave may damage the plate and the impulse impacted to the vehicle may destabilise the vehicle while it is on the move. It is therefore important to study the blast wave interaction with different shapes of armour plates. In general, the blast wave amplitude attenuates rapidly and the pulse width depends upon the amount of high explosive involved. The shape of armour plate becomes important when a blast wave interacts with it. Therefore, any design study may consider at least the following parameters: (a) explosive mass, (b) stand-off distance and (c) plate geometry. By carefully varying these parameters, a fair assessment for redesigning can be made. The modelling and optimization need to be cost effective as well as having a better level of accuracy both in models and numerical computation.

The investigations into the responses of structures due to blast loading have attracted attentions from researchers from all around the world for the past decades (Chen, Louca, \& Elghazouli, 2015; Fallah et al., 2014; Geretto, Chung, \& Nurick, 2015; Li, Wang, Zhu, Wu, \& Zhao, 2014; Ma, Xin, Hu, \& Zheng, 2013; Micallef, Fallah, Curtis, \& Louca, 2016; Othman et al., 2015; Shen, Lu, Wang, \& Zhao, 2010; Spiller, Packer, Seica, \& Yankelevsky, 2016; Wang \& Xiong, 2015; Zhang, Hao, \& Wang, 2015). An experimental and numerical simulation studies to mitigate the effects of mine explosion experienced by the underneath section of an armoured personal carrier by using ' $\mathrm{V}$-shaped' plates of $60^{\circ}, 90^{\circ}, 120^{\circ}, 150^{\circ}$ and $180^{\circ}$ angles, had been 
successfully performed (Chung, Langdon, Nurick, Pickering, \& Balden, 2012). They performed 35 small-scaled blast experimental tests on the V-shaped DOMEX 700 steel geometry plate and managed to obtain good agreements by using the numerical simulation i.e. AUTODYN to predict some of the experimental test results. It was observed that the $\mathrm{V}$-shaped plate of $60^{\circ}$ experienced the most reduced central deformation as compared to the other angles, which showed that it had managed to deflect the most amount of blast energy. Numerical simulation i.e. ABAQUS had been utilized to predict the effects of transient response and changing material properties of circular DOMEX $700 \mathrm{MC}$ steel plates against multiple blast loading experimental tests and good predictions were achieved (Henchie, Chung, Nurick, Ranwaha, \& Balden, 2014). Various masses of explosive were used with constant stand-off distance in the experimental blast tests and the circular plate was loaded with up to a maximum of 5 explosions per circular plate. It was found out that the strain hardening mechanical properties surged in the central area of the circular plate and around the perimeter of the circular plate where it was fully fixed during the experimental blast tests. A basic analytical method had been successfully proposed to predict the performance of water storage tank against blast loading (Wang \& Xiong, 2015). They managed to prove that their newly proposed LANGRANGIAN equation, which incorporated multiple deflection shape function had managed to give good prediction of peak load with differences of around $5 \%$ when compared to results obtained from numerical simulation i.e. LS-DYNA.

The objective of this paper is to produce series of blast loading numerical simulations of specified amount of TNT equivalent explosive located at the mid-point of a V-shaped plate (see Fig. 1 and Fig. 2). The numerical simulations fully utilized the experimental tests' parameters performed by researchers at the University of Cape Town, South Africa (Chung et al., 2012) and the experimental tests' mid-point deflections produced by these researchers are used to validate the predictions obtained by the numerical simulations using LS-DYNA.

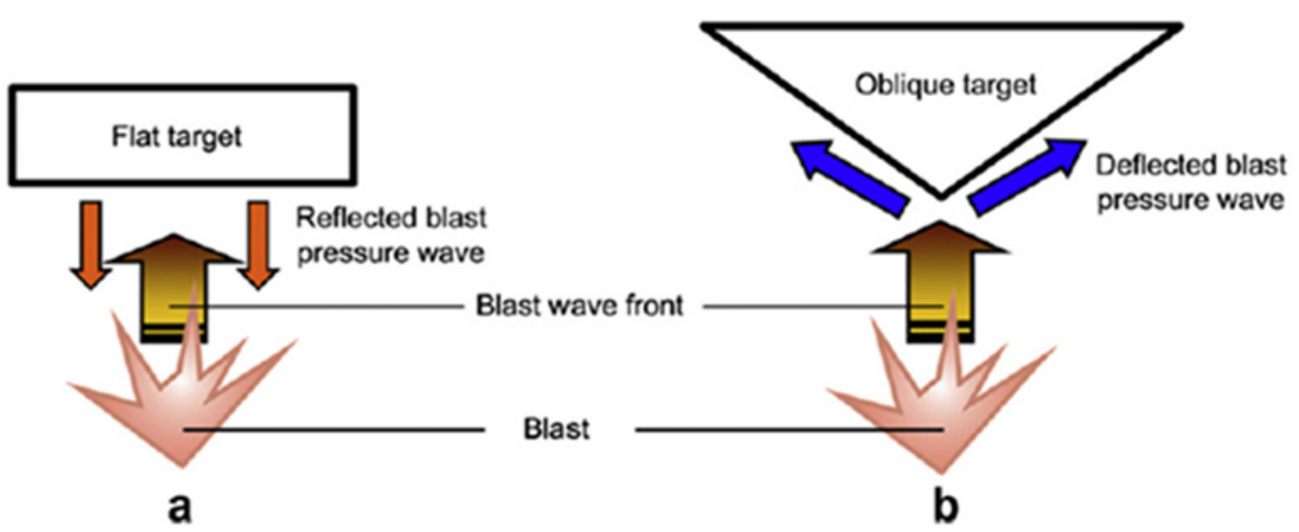

Figure 1. Flat target plate versus angled target plate for blast loading of structures (Chung et al., 2012)
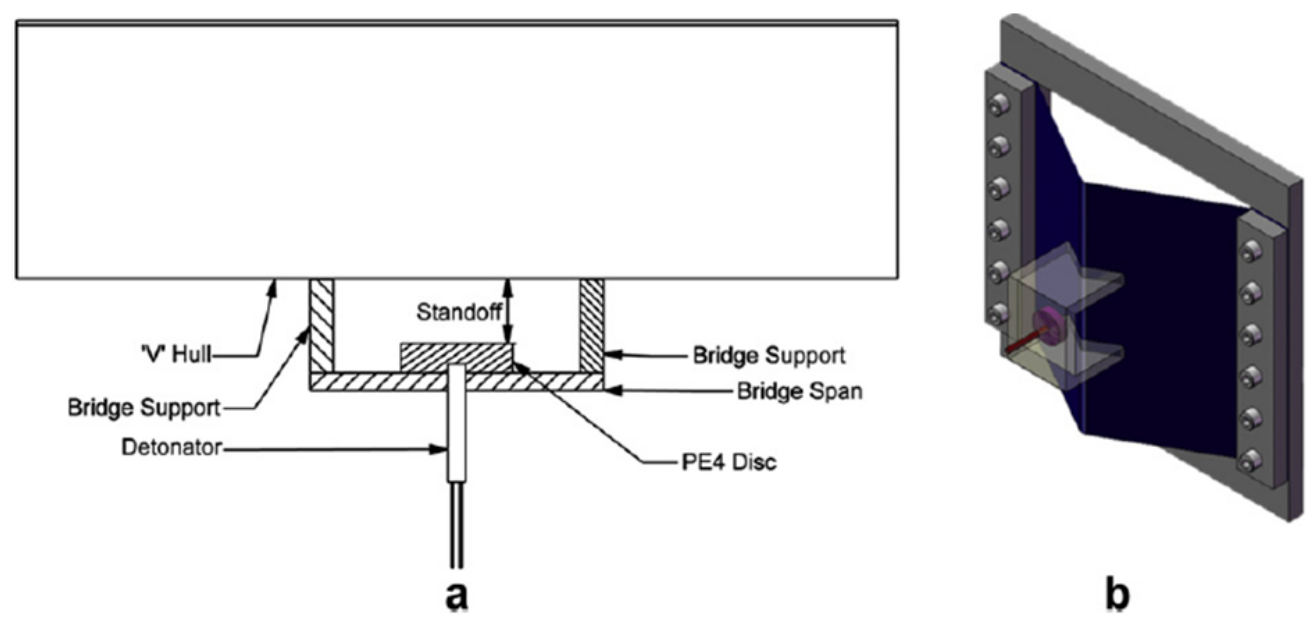

Figure 2. Experimental assembly of the blast loading of V-shaped plate (a) side view and (b) isometric view (Chung et al., 2012) 


\section{Method}

LS-DYNA, a leading general purpose multi-physics numerical simulation software developed distinctively for nonlinear transient dynamic finite element analysis using explicit time integration was used to simulate the blast loading of V-shaped plates in this study. Twenty-seven numerical simulations were performed to predict the mid-point deflections of previous experimental results for V-shaped plates consisted of $60^{\circ}, 90^{\circ}, 120^{\circ}, 150^{\circ}$ and $180^{\circ}$ included angles (Chung et al., 2012). In their experimental tests, each of the included angles had variable mass of explosives and stand-off distances that produced different magnitudes of the mid-point deflections on the V-shaped plates. The numerical simulation started with modelling the three dimensional V-shaped plate by using the shell elements in $\mathrm{x}, \mathrm{y}, \mathrm{z}$ Cartesian coordinate system. An equivalent TNT mass was then derived from the PE4 mass used in the experimental test and positioned at the mid-point of the vertex of the V-shaped plate. Static and dynamic mechanical properties of DOMEX 700 were applied to the three dimensional V-shaped numerical simulation models. The boundary conditions for both of the lower edges of the V-shaped plate were fully constrained in all six degree of freedoms since both edges were bolted in the experimental tests. The numerical simulations' models were then processed by using the LS-DYNA solver and the twenty-seven numerical simulations' mid-point deflections were then compared against the experimental tests data; more detailed steps are as shown in the following paragraphs.

\subsection{Geometry of the V-Shaped Plate}

Figure 3 shows a full three-dimensional finite element analysis $\mathrm{V}$-shaped model with a downward projecting area of $300 \mathrm{~mm} \times 300 \mathrm{~mm}$ with included angles of $60^{\circ}, 90^{\circ}, 120^{\circ}, 150^{\circ}$ and $180^{\circ}$ (Chung et al., 2012). Point A was the starting/reference point of the three dimensional model positioned at $(x=0, y=0, z=0)$ coordinate, point $B$ was the far end of the V-shaped positioned at $(x=-300 \mathrm{~mm}, \mathrm{y}=0, \mathrm{z}=0)$ coordinate, while point $\mathrm{C}$ was the suspended mid-point of the V-shaped length also known as the 'stand-off distance' upon which the explosive was located at $(x=-150 \mathrm{~mm}, \mathrm{y}=0, \mathrm{z}=34 \mathrm{~mm})$. The distance between point $A$ and point $\mathrm{B}$ was $300 \mathrm{~mm}$ and the distance between edge $\mathrm{E}$ and edge $\mathrm{D}$ was $300 \mathrm{~mm}$, which would enable the $\mathrm{V}$-shaped plate to produce a $300 \mathrm{~mm}$ x $300 \mathrm{~mm}$ area in the $\mathrm{x}-\mathrm{y}$ two-dimensional plane. Different masses of explosives and stand-off distances were applied to point $\mathrm{C}$, according to the parameters as specified in the experimental test data. The model was meshed with $5 \mathrm{~mm}$ x $5 \mathrm{~mm}$ element size which produced 5,126 elements. This $5 \mathrm{~mm}$ x $5 \mathrm{~mm}$ element size was chosen after the mesh convergence analysis had been performed, which produced acceptable mid-point deformation and time duration.

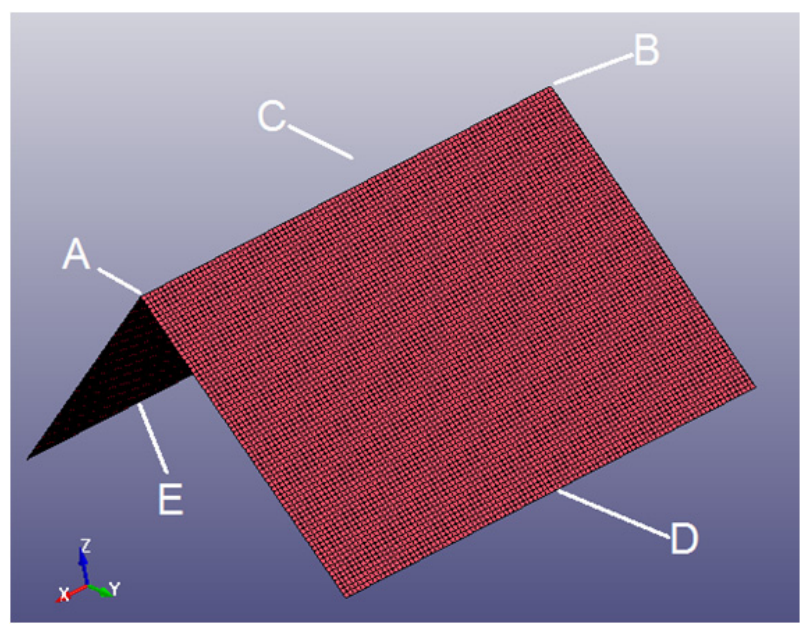

Figure 3. A three dimensional V-shaped finite element analysis model

\subsection{Explosive Parameters}

The experimental test utilized a cylindrical shape PE4 explosive to replicate the geometry of landmine, which had a $1.3 \mathrm{~kg}$ of TNT equivalent of explosive. *LOAD_BLAST_ENHANCED that used equivalent mass of TNT was utilized to model the blast loading effects in LS-DYNA. The equivalent mass of TNT (calculated from the respective amount of PE4 explosive used in the experimental test) that produced spherical air burst had to be positioned at a specific stand-off distance i.e. $(\mathrm{x}, \mathrm{y}, \mathrm{z})$ coordinate on top of the central midpoint location or at point $\mathrm{C}$ of the V-shaped specimen (see Fig. 3). ${ }^{*}$ LOAD_BLAST_SEGMENT_SET was then employed to 
represent both of the top surfaces of the V-shaped that were directly exposed to the blast loading of the idealised TNT explosive.

\subsection{Material Properties and Boundary Conditions of the V-Shaped Plate}

The V-shaped plate is made of DOMEX 700 steel (see Tab. 1) and to accommodate the large strain rate and large deformation of the specimen due to the blast loading effects, *MAT_SIMPLIFIED_JOHNSON_COOK (see Tab. 2) was used due to its advantage in reducing computational processing time. *SECTION_SHELL that utilized BELYTSCHKO-TSAY shell element formulation was used to model the V-shaped model with a $2 \mathrm{~mm}$ of shell thickness at the four corners of its nodes. Both edges of the model i.e. Edges ' $E$ ' and ' $D$ ' were fixed and constrained from moving in all directions i.e. in all of the $\mathrm{x}, \mathrm{y}, \mathrm{z}$, translational and $\mathrm{x}, \mathrm{y}, \mathrm{z}$, rotational directions to replicate the bolted edges of the specimen in the performed experimental tests.

Table 1. The mechanical properties for DOMEX 700 (Chung et al., 2012)

\begin{tabular}{ccc}
\hline Density $\left(\mathrm{kg} / \mathrm{m}^{3}\right)$ & Young's modulus $(\mathrm{GPa})$ & Poisson's ratio \\
\hline 7850 & 200 & 0.285 \\
\hline
\end{tabular}

Table 2. Johnson-Cook material properties for the V-shaped plate (Chung et al., 2012)

\begin{tabular}{cccc}
\hline $\mathrm{A}(\mathrm{MPa})$ & $\mathrm{B}(\mathrm{MPa})$ & $\mathrm{n}$ & $\mathrm{C}^{-1} \mathrm{~s}^{-1}$ \\
\hline 818 & 1423 & 0.987 & 0.014 \\
\hline
\end{tabular}

\subsection{Processing the Numerical Simulation}

*CONTROL_TERMINATION time of 30 milliseconds was chosen to fully capture the whole process of the blast loading for each of the numerical simulation test case. *BINARY_DBASE_D3PLOT with time interval between outputs of 5E-4 seconds was chosen to record the output data. The numerical simulation input file was then processed by using the LS-DYNA solver with hardware capabilities of Intel(R) Core(TM) i5-3210M CPU @ 2.5 $\mathrm{GHz}, 4.00 \mathrm{~GB}$ of RAM, which took around 5 minutes to complete. Upon the successful processing of the numerical simulation, the deflection of the V-shaped model due to the blast loading was obtained by selecting the 'Z-displacement' of the nodal mid-point displacement of the V-shaped model. All twenty-seven numerical simulation results of the mid-point deflections of the V-shaped models and compared against the experimental results are presented in the following section.

\section{Results}

Mesh convergence analysis had been performed to obtain the optimum element size that could give optimum results for the numerical simulations to predict all of the twenty-seven experimental blast load tests. Table 3 shows the mesh convergence analysis performed to predict the experimental test data of $90^{\circ}$ of included angle, $19 \mathrm{~g}$ of PE4, and $34 \mathrm{~mm}$ of stand-off distance. Three element sizes were utilized in the numerical simulation i.e. $1 \mathrm{~mm} \times 1 \mathrm{~mm}, 5 \mathrm{~mm} \times 5 \mathrm{~mm}$ and $10 \mathrm{~mm} \times 10 \mathrm{~mm}$ to predict the experimental mid-point deflection of the V-shaped due to blast loading. It was observed that element size of $5 \mathrm{~mm} \times 5 \mathrm{~mm}$ gave the best result with reasonable CPU time duration of around 3 minutes, thus this element size was chosen to be used to produce numerical simulations to predict all twenty-seven experimental tests data.

Table 3. Mesh convergence analysis performed to predict the experimental test data of $90^{\circ}$ of included angle, 19 $\mathrm{g}$ of PE4, and $34 \mathrm{~mm}$ of stand-off distance

\begin{tabular}{cccccc}
\hline Element size & $\begin{array}{c}\text { Number of } \\
\text { elements }\end{array}$ & $\begin{array}{c}\text { Time } \\
\text { duration }\end{array}$ & $\begin{array}{c}\text { Experimental mid-point } \\
\text { deflection }(\mathrm{mm}) \\
\text { (Chung et al., 2012) }\end{array}$ & $\begin{array}{c}\text { Numerical } \\
\text { simulation/LS-DYNA } \\
\text { mid-point deflection }(\mathrm{mm})\end{array}$ & $\begin{array}{c}\% \\
\text { Error }\end{array}$ \\
\hline $1 \mathrm{~mm} \times 1 \mathrm{~mm}$ & 127,628 & $\begin{array}{c}6 \text { hours } 30 \\
\text { minutes }\end{array}$ & 3.64 & 4.17 & +14.56 \\
$5 \mathrm{~mm} \times 5 \mathrm{~mm}$ & 5,126 & $\begin{array}{c}3 \text { minutes } \\
10 \mathrm{~mm} \times 10\end{array}$ & 3.64 & 3.11 & -15.0 \\
$\mathrm{~mm}$ & 1,300 & 32 seconds & 3.64 & 1.55 & -57.0 \\
\hline
\end{tabular}

Figure 4 shows some of the snapshots progressions of the deformation contours for the V-shaped plate upon blast loading for one of the numerical simulations' cases i.e., Test number Z5, included angle of $90^{\circ}, 19 \mathrm{~g}$ of PE4 and 
stand-off distance of $34 \mathrm{~mm}$. It could be observed that the $\mathrm{V}$-shaped plate was in its initial un-deformed geometrical shape at time, at $\mathrm{t}=0$ millisecond. Immediately after time, $\mathrm{t}=0$ millisecond until $\mathrm{t}=30$ milliseconds, the explosive had been detonated and it could be clearly seen that the mid-point area of the V-shaped located directly under the explosive had undergone visible deformations compared to other areas of the plate. The mid-point deformation of the V-shaped plate stabilized around and beyond time, $\mathrm{t}=10$ milliseconds and the overall registered deformation was recorded as $3.10 \mathrm{~mm}$ as shown in Figure 5.

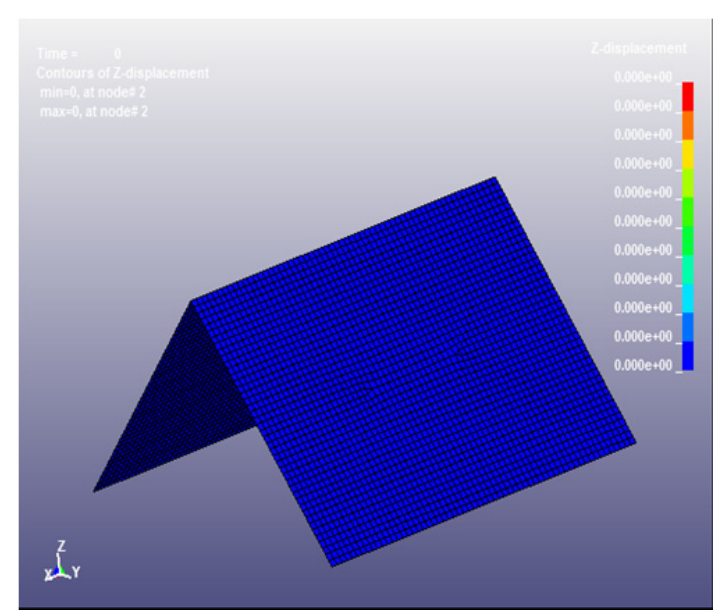

Time $=0$ millisecond

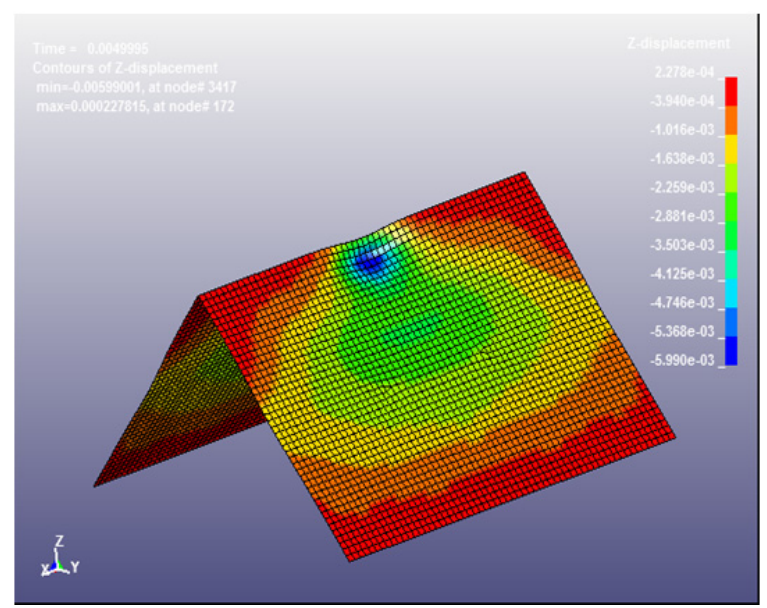

Time $=5$ milliseconds

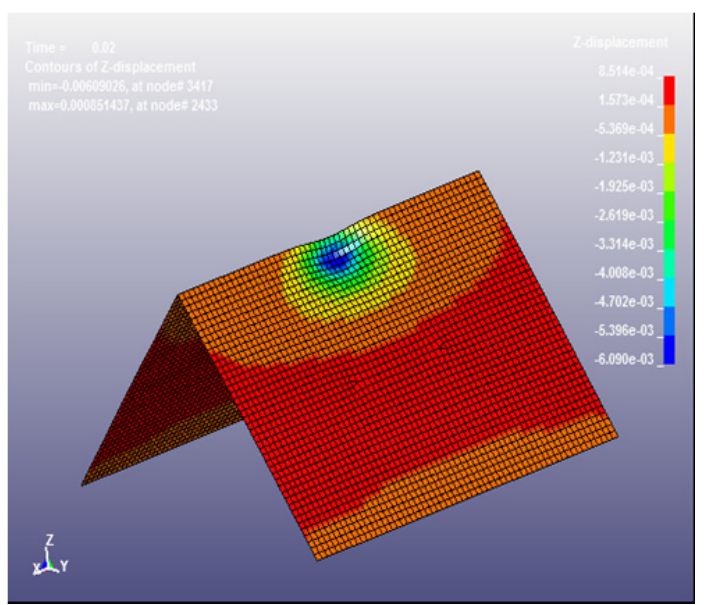

Time $=20$ milliseconds

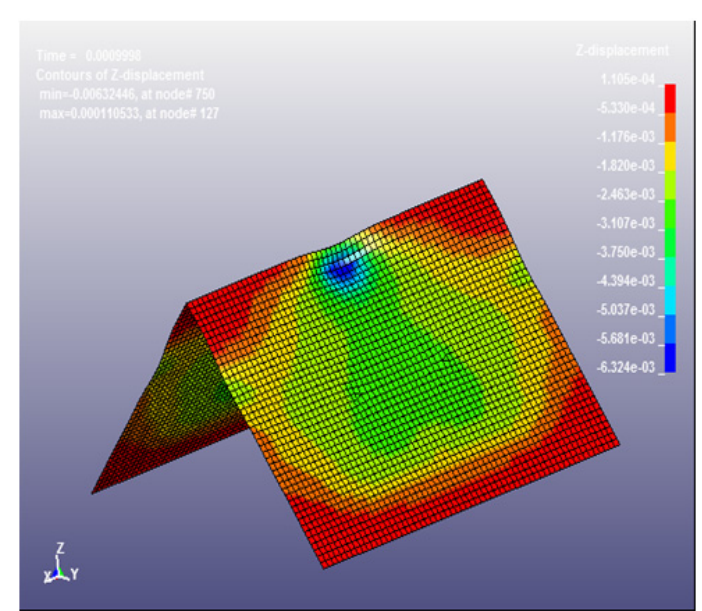

Time $=1$ millisecond

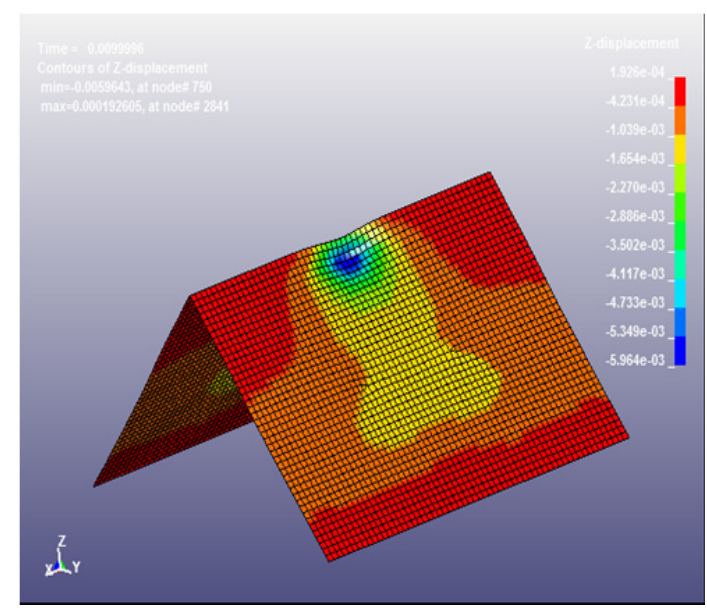

Time $=10$ milliseconds

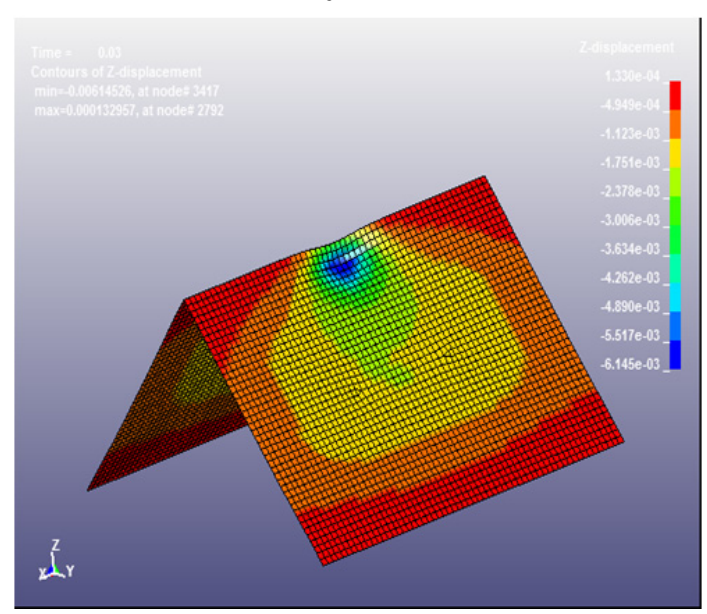

Time $=30$ milliseconds

Figure 4. The mid-point deformation contours of the V-shaped plate from 0 millisecond to 30 milliseconds for Test number Z5, included angle of $90^{\circ}, 19 \mathrm{~g}$ of PE4 and stand-off distance of $34 \mathrm{~mm}$ 


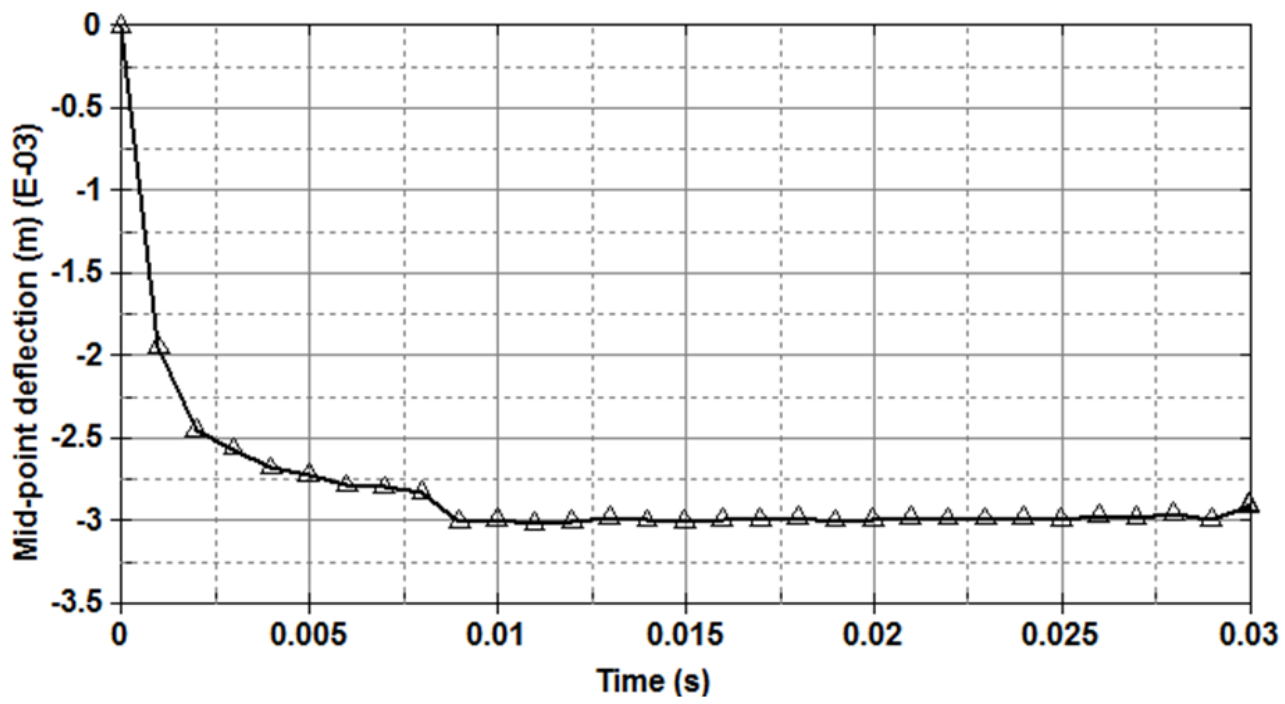

Figure 5. The mid-point deformation of the V-shaped plate plotted against time for time period of 30 milliseconds for Test number Z5, included angle of $90^{\circ}, 19 \mathrm{~g}$ of PE4 and stand-off distance of $34 \mathrm{~mm}$

Table 4 shows the numerical simulations' results that will be compared against the experimental tests data for twenty-seven mid-point deflections of $\mathrm{V}$-shaped plates due to blast loadings as shown by the test number from Test Number Z1 to Test Number Z27. All twenty-seven numerical simulations comprised of different combinations of included angle, mass of explosive and stand-off distance based on the parameters in the experimental tests. It could be observed that the numerical simulations managed to produce relatively good agreement for $\mathrm{V}$-shaped included angles of $60^{\circ}, 90^{\circ}, 120^{\circ}$ but as the included angles increased i.e. as the V-shaped plate became flat plate for $150^{\circ}$ and $180^{\circ}$ the percentage errors also increased. Nevertheless, even though the percentage errors were quite large as could be seen in Test number Z1 that had $+135 \%$ of errors, the real differences were quite 'small' as the dimensions involved were in ' $\mathrm{mm}$ ' i.e. $0.73 \mathrm{~mm}$ as predicted by the numerical simulation as opposed to $0.31 \mathrm{~mm}$ obtained in the experimental test. Generally, it could be concluded that the numerical simulations had managed to produce good agreement with experimental results where the overall average percentage differences is $26.6 \%$.

Table 4. Scaled down experimental test blast loading results used to validate the numerical simulation predictions

\begin{tabular}{ccccccc}
\hline $\begin{array}{c}\text { Test } \\
\text { number }\end{array}$ & $\begin{array}{c}\text { Included } \\
\text { angle }\end{array}$ & $\begin{array}{c}\text { Mass } \\
\text { of PE4 } \\
(\mathrm{g})\end{array}$ & $\begin{array}{c}\text { Stand-off } \\
\text { distance } \\
(\mathrm{mm})\end{array}$ & $\begin{array}{c}\text { Experimental mid-point } \\
\text { deflection }(\mathrm{mm})(\text { Chung } \\
\text { et al., 2012) }\end{array}$ & $\begin{array}{c}\text { LS-DYNA numerical } \\
\text { simulation prediction for } \\
\text { mid-point deflection }(\mathrm{mm})\end{array}$ & $\begin{array}{c}\% \\
\text { Error }\end{array}$ \\
\hline Z1 & $60^{\circ}$ & 19 & 34 & 0.31 & 0.73 & +135.5 \\
Z2 & $60^{\circ}$ & 29 & 34 & 1.50 & 1.36 & -9.3 \\
Z3 & $60^{\circ}$ & 40 & 34 & 2.23 & 2.90 & +30.0 \\
Z4 & $60^{\circ}$ & 45 & 34 & 2.02 & 3.90 & +93.0 \\
Z5 & $90^{\circ}$ & 19 & 34 & 3.64 & 3.10 & -14.8 \\
Z6 & $90^{\circ}$ & 14.5 & 50 & 0.71 & 0.47 & -33.8 \\
Z7 & $90^{\circ}$ & 29 & 34 & 9.03 & 8.10 & -10.3 \\
Z8 & $90^{\circ}$ & 29 & 50 & 2.56 & 15.92 & +14.1 \\
Z9 & $90^{\circ}$ & 40 & 34 & 11.65 & 18.70 & +34.8 \\
Z10 & $120^{\circ}$ & 19 & 34 & 17.74 & 46.30 & +2.0 \\
Z11 & $120^{\circ}$ & 29 & 26 & 38.33 & 38.90 & +20.8 \\
Z12 & $120^{\circ}$ & 29 & 34 & 31.01 & 32.00 & +25.4 \\
Z13 & $120^{\circ}$ & 29 & 42 & 24.76 & 16.80 & +29.2 \\
Z14 & $120^{\circ}$ & 29 & 50 & 14.29 & 50.70 & +17.6 \\
Z15 & $120^{\circ}$ & 35 & 34 & 42.66 & & +18.8 \\
\hline
\end{tabular}




\begin{tabular}{ccccccc}
\hline $\mathrm{Z} 16$ & $120^{\circ}$ & 40 & 34 & 51.09 & 62.20 & +21.7 \\
$\mathrm{Z} 17$ & $150^{\circ}$ & 5 & 34 & 6.28 & 2.98 & -52.5 \\
$\mathrm{Z} 18$ & $150^{\circ}$ & 10 & 34 & 17.51 & 23.50 & +34.2 \\
$\mathrm{Z} 19$ & $150^{\circ}$ & 12.5 & 34 & 28.47 & 32.50 & +14.2 \\
$\mathrm{Z} 20$ & $150^{\circ}$ & 14.5 & 34 & 28.81 & 38.60 & +34.0 \\
$\mathrm{Z} 21$ & $150^{\circ}$ & 17 & 34 & 30.97 & 46.90 & +51.4 \\
$\mathrm{Z} 22$ & $180^{\circ}$ & 5 & 34 & 8.42 & 6.78 & -19.5 \\
$\mathrm{Z} 23$ & $180^{\circ}$ & 10 & 34 & 16.12 & 27.5 & +70.6 \\
$\mathrm{Z} 24$ & $180^{\circ}$ & 14.5 & 34 & 24.26 & 40.7 & +67.8 \\
$\mathrm{Z} 25$ & $180^{\circ}$ & 19 & 34 & 38.72 & 51.4 & +32.7 \\
$\mathrm{Z} 26$ & $180^{\circ}$ & 21 & 34 & 37.38 & 55.5 & +48.5 \\
$\mathrm{Z} 27$ & $180^{\circ}$ & 23 & 34 & 37.88 & 59.4 & +56.8 \\
\hline
\end{tabular}

\section{Discussion}

\subsection{Effect of Explosive Geometrical Shape}

One of the possible source of errors is the geometrical shape of the explosive used in the numerical simulation. In their experimental blast tests, all of the explosives used were of cylindrical geometrical shape with varying masses of explosive with the detonator placed at the central location of the cylindrical explosive (see Fig. 2) but they did not specify the exact height of the cylindrical parameter. In the numerical simulation, under the *LOAD_BLAST_ENHANCED keyword, only the mass of the explosive and the $\mathrm{x}, \mathrm{y}, \mathrm{z}$ coordinates of the explosive were utilized, i.e. the program modeled the explosive as a spherical geometrical shape, thus the inability to model the exact parameters of cylindrical geometrical shape of the explosive and the limited capability of *LOAD_BLAST_ENHANCED keyword in modeling the explosive as a spherical geometrical shaped played a factor in contributing to the errors produce by the numerical simulations' results.

\subsection{Effect of Stand-Off Distance}

Another possible source of errors is the inconsistent usage of universal definition of the stand-off distance utilized in the experimental tests and numerical simulations. Figure 2(a) shows the measurement of the stand-off distance used in the experimental test where the stand-off distance represents the measured distance from the outer surface/perimeter of the cylindrical explosive to the vertex of the V-shaped plate. On the other hand, in another reference, the stand-off distance is defined as the measured distance from the most outer surface of a structure to the center point of a spherical shape explosive (Hetherington \& Smith, 1994). The non-standard measurement of the stand-off distance does play a significant effect on the outcome of the predicted deformation since a lower value of stand-off distance with constant mass of explosive will mean that the explosive is nearer to the structure thus the blast load will produce higher amount of deformation on the structure and a higher value of stand-off distance with constant mass of explosive will mean that the explosive is further away from the structure thus the blast load will result in lower value of deformation of the structure.

\subsection{Percentage Error Reduction}

Arbitrary Lagrangian Eulerian (ALE) method can be used in future work to further reduce the errors between the experimental and the numerical simulation data. The *LOAD_BLAST_ENHANCED keyword which was used in this paper utilized a spherical geometry shape of the explosive even though a cylindrical geometrical shape of explosive was used in the experimental test and this factor contributed to the large errors in some of the numerical simulation tests even though a large majority of the numerical simulations had managed to give good predictions with respect to the experimental test. Alternatively, by using the ALE method for future work, the exact dimensions of the three dimensional cylindrical geometrical shape of the explosive can be modeled together with air, explosive and the steel plate, thus will significantly reduce the differences between the numerical simulation predictions and the experimental tests data but the modeling of ALE is far more complex as compared to the *LOAD_BLAST_ENHANCED method.

\section{Conclusions}

A numerical simulation method with the utilization of LS-DYNA demonstrated case studies of V-shaped plate under blast loading. The numerical results are compared with experimental results from published literature showing close matching. The simulation method may be used for the parametric study of floor designing of personal armor vehicle. The mass of explosive mostly used in IEDs can be taken and simulations performed for different stand-off distance (floor-ground clearance), plate angle and plate thickness. A more thorough parametric 
study shall give the optimal design for the $\mathrm{V}$-shaped plate to mitigate blast loadings.

\section{Acknowledgments}

The authors would like to thank the Management, Research and Innovation Center, National Defense University Malaysia and the Ministry of Education, Malaysia for the sponsorship of Fundamental Research Grant Scheme (Grant number: FRGS/2/2014/TK01/UPNM/02/1)

\section{References}

Chen, A., Louca, L. A., \& Elghazouli, A. Y. (2015). Blast assessment of steel switch boxes under detonation loading scenarios. International Journal of Impact Engineering, 78, 51-63. http://dx.doi.org/10.1016/j.ijimpeng.2014.11.019

Chung, K. Y. S., Langdon, G. S., Nurick, G. N., Pickering, E. G., \& Balden, V. H. (2012). Response of V-shape plates to localised blast load: Experiments and numerical simulation. International Journal of Impact Engineering, 46, 97-109. http://dx.doi.org/10.1016/j.ijimpeng.2012.02.007

Fallah, A. S., Micallef, K., Langdon, G. S., Lee, W. C., Curtis, P. T., \& Louca, L. A. (2014). Dynamic response of Dyneema ${ }^{\circledR}$ HB26 plates to localised blast loading. International Journal of Impact Engineering, 73, 91-100. http://dx.doi.org/10.1016/j.ijimpeng.2014.06.014

Geretto, C., Chung Kim Yuen, S., \& Nurick, G. N. (2015). An experimental study of the effects of degrees of confinement on the response of square mild steel plates subjected to blast loading. International Journal of Impact Engineering, 79, 32-44. http://dx.doi.org/10.1016/j.ijimpeng.2014.08.002

Henchie, T. F., Chung, K. Y. S., Nurick, G. N., Ranwaha, N., \& Balden, V. H. (2014). The response of circular plates to repeated uniform blast loads: An experimental and numerical study. International Journal of Impact Engineering, 74, 36-45. http://dx.doi.org/10.1016/j.ijimpeng.2014.02.021

Li, X., Wang, Z., Zhu, F., Wu, G., \& Zhao, L. (2014). Response of aluminium corrugated sandwich panels under air blast loadings: Experiment and numerical simulation. International Journal of Impact Engineering, 65, 79-88. http://dx.doi.org/10.1016/j.ijimpeng.2013.11.002

Ma, L., Xin, J., Hu, Y., \& Zheng, J. (2013). Ductile and brittle failure assessment of containment vessels subjected to internal blast loading. International Journal of Impact Engineering, 52, 28-36. http://dx.doi.org/10.1016/j.ijimpeng.2012.09.004

Micallef, K., Fallah, A. S., Curtis, P. T., \& Louca, L. A. (2016). On the dynamic plastic response of steel membranes subjected to localised blast loading. International Journal of Impact Engineering, 89, 25-37. http://dx.doi.org/10.1016/j.ijimpeng.2015.11.002

Othman, M. Z., Yuan, L. C., Yusoff, M. A. M., Ghani, A. R. A., Koslan, M. F. S., Jelani, J., \& Zaidi, A. M. A. (2015). Numerical Simulations of Exposed Circular Surface of Rolled Homogeneous Armor Steel Plates Subjected to Blast Loadings by using AUTODYN 2D. Modern Applied Science, 9(3). http://dx.doi.org/10.5539/mas.v9n3p216

Shen, J., Lu, G., Wang, Z., \& Zhao, L. (2010). Experiments on curved sandwich panels under blast loading. $\begin{array}{llll}\text { International Journal of Impact } & \text { Engineering, }\end{array}$ http://dx.doi.org/10.1016/j.ijimpeng.2010.03.002

Spiller, K., Packer, J. A., Seica, M. V., \& Yankelevsky, D. Z. (2016). Prediction of annealed glass window response to blast loading. International Journal of Impact Engineering, 88, 189-200. http://dx.doi.org/10.1016/j.ijimpeng.2015.10.010

Wang, Y., \& Xiong, M. X. (2015). Analysis of axially restrained water storage tank under blast loading. International Journal of Impact Engineering, 86, 167-178. http://dx.doi.org/10.1016/j.ijimpeng.2015.07.012

Zhang, X., Hao, H., \& Wang, Z. (2015). Experimental study of laminated glass window responses under impulsive and blast loading. International Journal of Impact Engineering, 78, 1-19. http://dx.doi.org/10.1016/j.ijimpeng.2014.11.020

\section{Copyrights}

Copyright for this article is retained by the author(s), with first publication rights granted to the journal.

This is an open-access article distributed under the terms and conditions of the Creative Commons Attribution license (http://creativecommons.org/licenses/by/4.0/). 